\title{
Learning from a rapid transition to remote emergency teaching: Developing a typology of online business education designs
}

\author{
Elaine Huber, Celina McEwen, Peter Bryant, Matthew Taylor, Natasha Arthars and \\ Henry Boateng \\ University of Sydney
}

\begin{abstract}
Many universities had to pivot their teaching into an online space in response to the COVID-19 health crisis. How can we leverage the lessons learned from our design of these spaces to provide superior student learning experiences? This study describes the development of a classification system to appraise our rapidly transitioned online units of study. Underpinned by active learning pedagogy, 234 online learning sites from a leading Australian Business School were reviewed and three types of sites emerged, content, student and teacher-centred. The quality of these online sites were evaluated using a modified framework from the literature focusing on elements of design across five domains. Findings indicated that the overall range of quality of sites was mirrored across all three types, with the majority categorised as 'good'. Analysis of the design elements of this typology will help build capacity in the design of online learning environments and guide pedagogical practice in business education.
\end{abstract}

Keywords: COVID19; online learning design; active learning; educational development; emergency remote teaching

\section{Introduction}

The COVID-19 health crisis has necessitated rapid pivoting by universities from face to face and blended learning modes to purely online, distance modes of education (Doucet, Netolicky, Timmers \& Tuscano, 2020). It has also been termed emergency remote teaching (ERT) whereby "the primary objective ... is not to re-create a robust educational ecosystem but rather to provide temporary access to instruction and instructional supports in a manner that is quick to set up and is reliably available during an emergency or crisis" (Hodges, 2020, p. 6). Pragmatically, the institutions who pivoted their learning online were able to successfully complete the activities required within the semester to ensure the short-term impacts on student progression due to COVID-19 were minimised (Czerniewicz, 2020). However, from a teaching staff and students' perspective, anecdotal evidence (shared on social media, for example) presents a more complex picture. Indeed, this transition or ERT, has been dubbed 'The Big Experiment' (Salmon et al., 2020) because even though universities have increasingly been delivering short and long courses online, none were prepared to deliver all their teaching online and with such short notice (Hodges et al., 2020). For example, the lockdown measures implemented to manage the COVID-19 health crisis required teaching staff and students to work and study from their homes in Australia and overseas, creating the additional challenge of the blurring of professional and personal boundaries (Rapanta, Botturi, Goodyear, Guàrdia \& Koole, 2020). The sudden need to shift synchronous communication (normally conducted face to face), to the medium of web conferencing has given rise to 'Zoom fatigue', "an array of physical and psychological factors that combine to make our synchronous online communications less effective and wrought with discomfort" (Schroeder, 2020, para. 2). Moreover, an early review of the impact of this shift to online learning (Armour et al., 2020) found that if maintained for an extended time period, the arrangements implemented in response to COVID-19 could have long lasting negative effects on students' learning outcomes.

This transition will have repercussions and will need to be managed over several years, and it is crucial to reflect on this pedagogically (Siemens, 2020). To prepare for what Siemens (2020) has called the 'second hump', or the post-emergency measures, Sydney University Business School (USBS), conducted a study to understand how the different models and practices of online learning used in the semester 12020 pivot impacted positively or negatively on students' learning experiences. As part of the study, we analysed students' feedback about their satisfaction with their online learning experience, which we compared with data gathered about the different types of online learning methodologies implemented. This concise paper focuses on one part of the study: the appraisal of USBS units of study delivered in the first half of 2020. In what follows, we present the study's 
methodology, reporting on our work in progress with a focus on how we developed our emerging typology of online learning environments and what constitutes 'good' elements of design. It is envisaged this work will help guide pedagogical practice in business education that lies in the post-COVID world.

\section{Methodology}

This project was theoretically informed by an active learning perspective. Active learning techniques require students to "engage in higher order learning, thinking and doing while learning from their peers, and applying the information to real-life situations" (Tanis, 2020, p. 3). Although active learning has not typically been associated with online learning, it can be incorporated by using well-designed discussions and group work (Khan, Egbue, Palkie \& Madden, 2017). By positioning the learner at the centre of the design of learning and teaching (L\&T) activities, active learning improves learning outcomes as well as student's attitudes towards learning (Khan et al., 2017).

This educational development project used an evaluation framework tailored to the study's needs, which we called the unit design checklist. To develop a typology of USBS online learning sites, we conducted a mapping exercise that consisted of reviewing these sites for units of study taught in the first half of 2020 with the checklist. Sites were reviewed at one point in time, rather than over the duration of the semester, which means that in some instances we were only partially able to gauge the range of pedagogical activities used by teaching staff.

234 units delivered in the first half of 2020 were reviewed with a focus on elements of design, including the learning management system's (LMS) functions as well as implemented pedagogies. The sites were described in relation to their content (headers and labels) and also in terms of layout and design. In the review process, the use of Canvas administrative functions was ignored (i.e., 'settings' and 'attendance'). The use of plug-ins was also noted, specifying whether they were embedded or accessed via redirection. Pedagogical annotations were also used to signal the presence of synchronous activities, scaffolding (progressive release of learning activities and elements), or self-regulated learning (SRL) (activities or tasks that support taking control of own learning, for example, peer or self-assessment, learning contracts).

Data collected about each site was then reviewed and sites clustered according to emerging themes to determine the range and types of sites. As an educational development project aimed at improving online learning designs, in addition to needing to determine the different types of sites, we also needed to evaluate the quality of these sites. This was carried out using a framework adapted from Johnson et al.'s (2019) revised course evaluation checklist developed for Canvas users as a foundational and customisable tool to guide and to help improve the design of online learning sites. The team tailored Johnson et al.'s (2019) checklist to our institutional context (and by adding the domain column) into what we called the unit design checklist (Table 1) with levels being accumulative, i.e., good sites include all basic elements. This unit design checklist was used alongside the list of types of sites emerging from the review to form the base framework of the typology.

Table 1. Unit design checklist adapted from Johnson et al. (2019)

\begin{tabular}{|l|l|l|}
\hline Level & Item & Domain \\
\hline Basic & Home Page & Look \& Feel \\
\cline { 2 - 3 } & Navigation & Organisation \\
\cline { 2 - 3 } & Key learning information & Organisation \\
\cline { 2 - 3 } & Course information & Content \\
\cline { 2 - 3 } & Varied learning activities & Pedagogy \\
\cline { 2 - 3 } & Instructions & Organisation \\
\cline { 2 - 3 } & Contact information & Organisation \\
\cline { 2 - 3 } & Links & Technology \\
\hline \multirow{5}{*}{ Good } & Modular/chunked information & Pedagogy \\
\cline { 2 - 3 } & Feedback & Pedagogy \\
\cline { 2 - 3 } & Outcomes & Pedagogy \\
\cline { 2 - 3 } & Institutional resources & Content \\
\cline { 2 - 3 } & Visual representation & Look \& Feel \\
\hline \multirow{5}{*}{ Excellent } & Scaffolding & Pedagogy \\
\cline { 2 - 3 } & Varied assessment tasks & Connection \\
\cline { 2 - 3 } & Sense of community & \\
\hline
\end{tabular}




\begin{tabular}{|l|l|l|}
\hline & Marking criteria & Organisation \\
\hline Bookended text & Content \\
\hline Style and structure & Look \& Feel \\
\hline Naming convention & Organisation \\
\hline Personalised learning & Pedagogy \\
\hline Document Preview & Technology \\
\hline External tool relevance & Technology \\
\hline Sound & Content \\
\hline Accommodation & Content \\
\hline Safety & Organisation \\
\hline
\end{tabular}

\section{Results and discussion}

This review surfaced three broad types of sites based on what drives the design when considered through the lens of an active learning pedagogy. The types were: content-centred; teacher-centred; and student-centred. Content-centred sites were designed around the content specific to the discipline and from the perspective of the material covered. Most often, this meant a single-entry point (e.g., horizontal and vertical navigational bars, hyperlinks etc.) and a structure based on material format. Teacher-centred sites were designed from the perspective of teaching staff or to cater for the 'ideal' or 'traditional' students' learning approaches. They mostly included single entry points or multiple entry points suited to one way or two-way communication with a focus on peer-to-peer exchanges. Student-centred designs catered for students from diverse backgrounds, experiences, approaches, needs and abilities. These sites had two-way communication and multiple entry points. Our review of the 234 active sites found that more than half (54\%) of the sites were mostly content-centred, almost a third (30\%) were mostly student-centred and a minority (16\%) were mostly teacher-centred (Figure 1$)$.

In addition to categorising the sites according to their features, we also categorised them in relation to their L\&T qualities based on the unit design checklist. Accordingly, the different types of sites were categorised as:

Limited - when they did not include all the basic elements; Basic - when they only met the basic criteria; Good - when they met all the basic and most of the good elements of design; and Excellent - when they met the basic and a majority of the good and excellent criteria. Overall, more than two-thirds (68\%) of sites were categorised as 'good', a little over one-fifth (23\%) of sites were categorised as 'basic'. At either end of the spectrum, only a few sites were categorised as 'limited' $(7 \%)$ and 'excellent' $(2 \%)$. This overall range of quality of sites was mirrored across all three types, with the majority of sites categorised as 'good' (Figure 1).

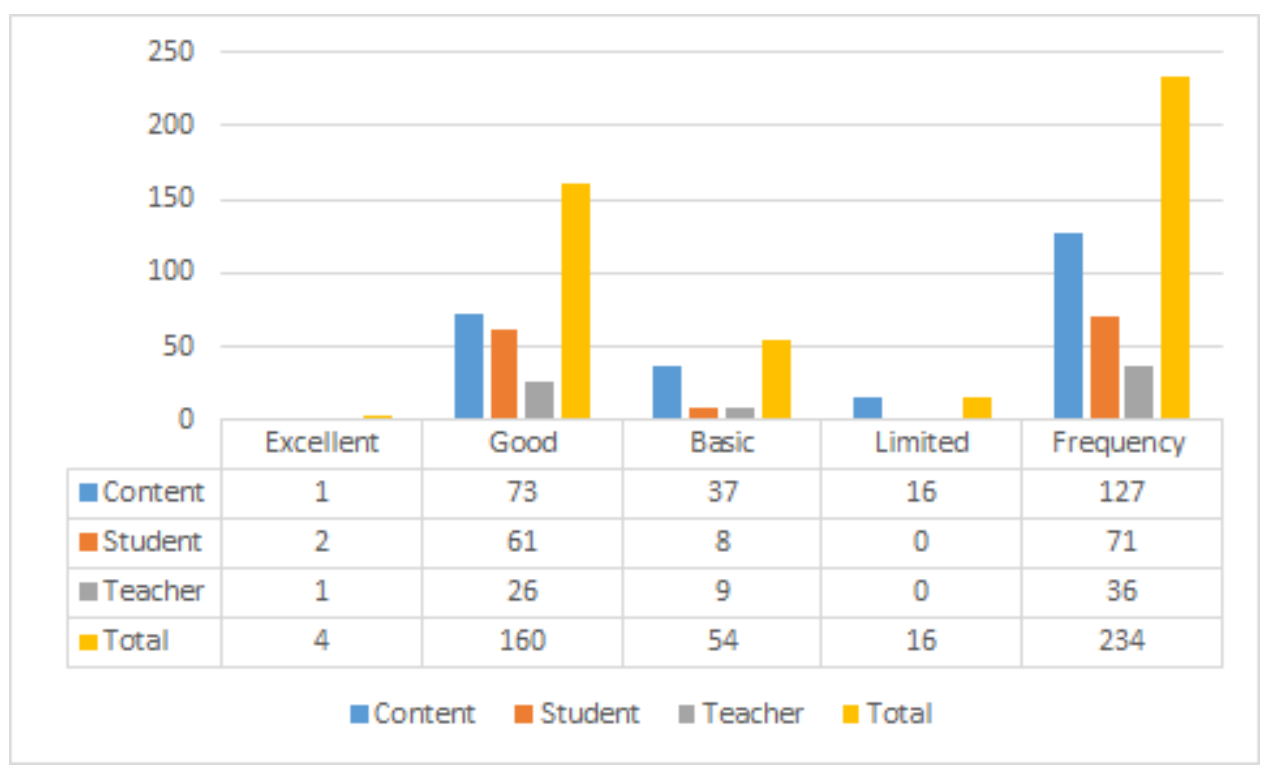

Figure 1. Number of sites per type and quality

Although content-centred sites were mostly 'good', this type also included all the sites categorised as 'limited'. As a content-centred site designed from the perspective of the material covered, 'limited' sites often had no discussion board, no group or collaborative projects. They also lacked visible communication encouraging 
interactions between peers and with staff. In addition to that, these sites showed limited concern with the aesthetic elements of online learning (e.g., no visuals) and limited amount of expanded instructions (e.g., presence of dot points over narrative text). Further, these limited content-centred sites were frequently designed 'against the grain' of the template making them difficult or counter-intuitive to navigate (e.g., not following the common template, using module as home page, creating separate pages instead of using the pre-defined pages/functions). In some extreme cases, the content provided was outdated, simply because unit coordinators omitted to remove information or content from previous semesters from the site.

The sites assessed as mostly teacher-centred were designed from the perspective of teaching staff, with one-way and two-way communication mostly focused on peer-to-peer exchanges, but also single-entry points or multiple entry points suited to the 'ideal' or 'traditional' students learning approaches. Overall, the teacher-centred sites only provided narrow opportunities to ask teaching staff questions and had ad hoc evidence of the implementation of participatory and SRL activities. The sites that were mostly student-centred, designed from the perspective of students from a variety of backgrounds, approaches, needs and abilities, always included twoway communication channels and multiple entry points to navigate to activities and content.

Examples of excellent teacher or student-centred sites made extensive use of discussion boards as well as deliberate use of collaborative, participatory and SRL tasks and activities. Exchanges between staff and students and among students were encouraged (e.g., through assignment or role modelling). They also made great use of the standard template and Canvas functions and plugins. They were easy and intuitive to navigate (e.g., included multiple entry points to cater for different uses). Finally, they showed that teaching staff scheduled time with students one-on-one or in groups. This finding aligns with one of the national guidelines for improving student outcomes in online learning (Stone, 2017, p. 4). Explicitly value and support the vital role of 'teacher-presence'. With a focus on content, these sites provided up-to-date information, as well as clear, streamlined and centralised access to information.

The analysis of the design elements of sites categorised as 'good' helped us distinguish between 'good' online learning environments in theory (i.e., according to the unit design framework) and 'good' sites in practice. In practice, we found that 'good' sites were defined by their ease of navigation (occurring 68 times out of the total of 158 'good' sites), rich in content (66), their support and promotion of active engagement with content, peers and staff (32) and the presence of two-way communication channels (20).

In relation to pedagogy, content, organisation and connection, the majority of 'good' sites in practice tended to support SRL through the presence of a combination of autonomous and guided L\&T activities. They promoted participatory and collaborative learning through group work and discussions, and they included both synchronous and asynchronous activities, such as live lectures or tutorials and recorded lectures or external podcasts and other videos. Further, they provided access to a range of student services and additional L\&T material and resources.

Overall, what seemed to be missing compared with the theory of 'good' online learning design were elements that could symbolise staff presence, even when not physically connected in the classroom (e.g., the use of photos of staff, alternative ways of contacting staff besides through discussion boards, a sense of collaboration or teamwork among teaching staff, short turnaround time to respond to students' questions, and welcome messages in addition to the brief outline of the unit). These elements are closely linked to Garrison, Anderson and Archer's (1999) community of inquiry (COI) theory that stipulates that a meaningful learning experience requires developing a sense of community between students and teachers through teacher presence, social presence and cognitive presence. Having a community in online settings increases students' satisfaction because it supports quality collaboration, including information dissemination and access to support (Rovai, 2000).

Broadly speaking, in relation to the look and feel of the site, 'good' sites in practice included: content that required no more than two scrolls per page; functional use of hyperlinks (i.e., internal and external, as well as redirected or embedded); a consistent look and feel with the general use of the common template; use of sign posting to help to navigate the site when it diverged from the standard template; structured text with the use of headers, icons, minimal use of colour and multi-media; and chunking of content most often around weekly activities. To help reduce the discrepancy between 'good' design and 'good' experience would have required an augmented use of elements of visual representation and a more consistent and integrated use of plugged in platforms to provide a seamless experience. 
Although some academics consider polished, visually elaborate presentations to be a method for hiding a weak argument (Lynch, 2009), research shows that a websites' credibility is judged within seconds based on elements of website design (Robins \& Holmes, 2008) and that what is aesthetically pleasing is judged as usable (Mbipom \& Harper, 2009). More importantly, websites' design has also been found to affect student's motivation to engage and persist with online learning (Glore, 2011) and even improve online learning environments (Hancock, 2004) and enhance understanding of learning material (Glore, 2011).

\section{Conclusion and next steps}

This paper has demonstrated how a typological classification exercise can be used to understand the relative proportion of student, teacher and content-centred LMS sites that were developed in response to the COVID-19 crisis. We found over half of the sites to be content-centred and using our qualitative assessment, we then demonstrated that almost three-quarters of sites were deemed as 'good'. Given the rapid, turbulent nature of placing education entirely online during the pandemic, these results are encouraging.

The identification of typologies and their relative effectiveness can be useful in helping improve teaching staff's preparedness and students' online learning experiences. Combined with an analysis of students' feedback data mapped against our typology of the online site designs, we expect to be able to better determine the key pedagogical value of all three types of online learning sites and the elements of design best suited to each type.

Alongside their lived experiences of ERT, these findings may help teaching staff as well as educational developers and designers further enhance the student experience both online and face-to-face. There likely will be future public health and safety concerns, possibly due to natural disasters (Hodges et al., 2020) therefore the skills developed during this pandemic will not be wasted and may indeed become part of ongoing professional development requirements.

\section{References}

Armour, D., Blackmore, H., Brown, N., Clinton, J., Geelan, D., Martin, A., Miller, J., Mulcahy, M., Prestridge, S., Selwyn, N., Taylor-Guy, P., Thomas, J., West, D., Wilson, R., (2020). Rapid Research Information Forum: Differential learning outcomes for online versus in-class education. Australia: Office of the Chief Scientist (Australia).

Czerniewicz, L. (2020). What we learnt from "going online" during university shutdowns in South Africa. Phil on EdTech

Doucet, A., Netolicky, D., Timmers, K., \& Tuscano, F. J. (2020). Thinking about Pedagogy in an Unfolding Pandemic: And Independent Report on Approaches to Distance Learning During COVID19 School Closures, 1-58.

Garrison, D. R., Anderson, T., \& Archer, W. (1999). Critical inquiry in a text-based environment: Computer conferencing in higher education. The Internet and Higher Education, 2(2-3), 87-105.

Glore, P. (2011). Identifying motivational strategies to engage undergraduate learning in web-based instruction.

Paper presented at the E-Learn: World Conference on E-Learning in Corporate, Government, Healthcare, and Higher Education.

Hancock, D. (2004). Improving the environment in distance learning courses through the application of aesthetic principles (Education Specialist Thesis). https://scholarcommons.usf.edu/etd/1065

Hodges, C., Moore, S., Lockee, B., Trust, T., \& Bond, A. (2020). The difference between emergency remote teaching and online learning. Educause Review, 27.

Johnson, D., Keefe, E., Philips, L., Lattke, M., \& Gibbons, T., (2019). Course Evaluation Checklist v2.0. Salt Lake City, UT: Canvas. Retrieved from https://community.canvaslms.com/groups/designers/blog/2018/06/29/course-evaluation-checklist

Khan, A., Egbue, O., Palkie, B., \& Madden, J. (2017). Active learning: Engaging students to maximize learning in an online course. Electronic Journal of E-Learning, 15(2), 107-115.

Lynch, P. (2009). Visual decision making. A List Apart: For People Who Make Websites, 286. Retrieved from http://www.alistapart.com/articles/visual-decision-making/

Mbipom, G., \& Harper, S. (2011). The interplay between web aesthetics and accessibility. Paper presented at 
the proceedings of the 13th international ACM SIGACCESS conference on Computers and accessibility.

Rapanta, C., Botturi, L., Goodyear, P., Guàrdia, L., \& Koole, M. (2020). Online University Teaching During and After the Covid-19 Crisis: Refocusing Teacher Presence and Learning Activity. Postdigital Science and Education, 1-23.

Robins, D., \& Holmes, J. (2008). Aesthetics and credibility in web site design. Information Processing \& Management, 44(1), 386-399.

Rovai, A. P. (2000). Building and sustaining community in asynchronous learning networks. The Internet and Higher Education, 3(4), 285-297.

Salmon, G., Dickinson, J., Leach, M., Greatrix, P., Kernohan, D., Parrott, E., ... Brabner, R. Testing the equivalence of online and on campus learning. Retrieved from https://wonkhe.com/blogs/testing-the-equivalence-of-online-and-on-campus-learning/

Schroeder, R. (2020). Are You a Victim of Zoom Fatigue? Retrieved 28 June 2020, from https://www.insidehighered.com/digital-learning/blogs/online-trending-now/are-you-victim-zoomfatigue

Siemens, G. [@GSiemens]. (2020, April 1). Faculty and staff need to prepare for a "two hump" problem with going online. [Tweet]. Twitter. https://twitter.com/gsiemens/status/1245258342332686336?s=20

Stone, C. (2017). National Guidelines for Improving Student Outcomes in Online Learning. JANZSSAJournal of the Australian and New Zealand Student Services Association, 25(2), 2621.

Tanis, C. J. (2020). The seven principles of online learning: Feedback from faculty and alumni on its importance for teaching and learning. Research in Learning Technology, 28(0). doi:10.25304/rlt.v28.2319

Huber, E., McEwan, C., Bryant, P., Taylor, M., Arthers, N. \& Boateng, H. (2020). Learning from a rapid transition to remote emergency teaching: Developing a typology of online business education designs. In S. Gregory, S. Warburton, \& M. Parkes (Eds.), ASCILITE's First Virtual Conference. Proceedings ASCILITE 2020 in Armidale (pp. 119-124). https://doi.org/10.14742/ascilite2020.0142

Note: All published papers are refereed, having undergone a double-blind peer-review process.

The author(s) assign a Creative Commons by attribution licence enabling others to distribute, remix, tweak, and build upon their work, even commercially, as long as credit is given to the author(s) for the original creation.

(C) Huber, E., McEwan, C., Bryant, P., Taylor, M., Arthers, N. \& Boateng, H. 2020 